\title{
ESSE ESTRANHO/ESTRANGEIRO CONHECIDO QUE NOS HABITA
}

\author{
THIS STRANGER/FOREIGN ACQUAINTANCE THAT DWELLS US
}

Renata Flecha*

\section{RESUMO:}

A Psicanálise se debruça, ao longo de sua história, sobre a temática do estrangeiro, ou ainda, do estranho, que, é ao mesmo tempo um conhecido que nos habita desde sempre. Assim, para encaminhar as reflexões aqui propostas nos remeteremos, inicialmente, a um texto de Freud, de 1919, de nome "Das Unheimliche", ou "O estranho". O estranho se articula com o inconsciente e suas manifestações, que produzem no sujeito um sentimento de ultrapassagem, como se fora atropelado por um outro sujeito que ele desconhece, um estranho, que se impõe em seu discurso. Uma outra manifestação do estranho, em sua, digamos, radicalidade, se apresenta através da loucura. $\mathrm{O}$ estranho se vincula ao desejo que para a Psicanálise remete a uma ordem simbólica. Ele sempre demarca uma falta e não para um objeto que possa ser empiricamente considerado. Assim, deslocando de objeto em objeto, o desejo desliza numa série infinita, numa satisfação nunca atingida e para sempre adiada. Freud nos ensinou que o objeto do desejo é um objeto perdido, uma falta, e que esse objeto perdido para sempre mantém sua presença como falta. A falta é, assim, a condição fundamental do sujeito e de sua humanidade.

PALAVRAS-CHAVE: Das Unheimliche. Estranho. Inconsciente. Loucura. Psicanálise.

\begin{abstract}
:
Throughout its history, Psychoanalysis has focused on the theme of the foreigner, or of the stranger, who is at the same time an acquaintance who inhabits us forever. Thus, to refer to the reflections proposed here, we refer initially to a 1919 Freud text, called "Das Unheimliche", or "The Stranger". The Stranger articulates with the unconscious and its manifestations, which produce in the subject a feeling of overcoming, as if he had been run over by another subject he does not know, a stranger who imposes himself in his speech. Another manifestation of the stranger, in his, say, radicality comes through madness. The stranger is linked to the desire that for psychoanalysis refers to a symbolic order. It always marks a fault and not an object that can be empirically considered. Thus, shifting from object to object, desire slides in an infinite series, a satisfaction never reached and forever deferred. Freud taught us that the object of desire is a lost object, a fault, and that this lost object forever preserves its presence as a fault. Failure is thus the fundamental condition of the subject and his humanity.
\end{abstract}

KEY WORDS: Das Unheimliche. Weird. Unconscious. Madness. Psychoanalysis.

\footnotetext{
* Doutora em Educação (UFMG), Psicanalista. Professora do Departamento de Ciência da Religião da Pontifícia Universidade Católica de Minas Gerais. E-mail: rflecha@uai.com.br.
} 


\section{INTRODUÇÃO}

A Psicanálise se debruça, ao longo de sua história, sobre a temática do estrangeiro, ou ainda, do estranho, que, é ao mesmo tempo um conhecido que nos habita desde sempre. Assim, para encaminhar as reflexões aqui propostas nos remeteremos, inicialmente, a um texto de Freud, de 1919, de nome "Das Unheimliche", ou "O estranho".

Esse texto, "Das Unheimliche" ou "O estranho" é um escrito de Freud objeto de análise, não só de psicanalistas, mas também, por exemplo, daqueles que se inserem no campo literário. Segundo Martini e Coelho Júnior (2010),

[...] é um escrito de difícil classificação na obra freudiana, não o encaixamos muito bem seja numa vertente clínica, seja numa vertente metapsicológica considerada em sua dimensão teórica. Restaria esse lugar difuso que remete à cultura em geral, mas seu destino um tanto errático revela, assim um valor que é subutilizado nas rodas psicanalíticas.

Em sua tradução, Unheimliche pode apresentar diferenças tais como: estrangeiro, hora ou lugar estranho, inquietante, desconfortável, sombrio, obscuro, assombrado, repulsivo, sinistro, suspeito, lúgubre, demoníaco, sendo importante ressaltar que Freud apoia-se numa ambiguidade linguística que produz um efeito curioso: heimliche pode ser o familiar, mas denota também algo de ordem secreta e oculta, o que, de forma paradoxal, torna tal palavra próxima de seu oposto, Unheimliche. Martini e Coelho Júnior (2010), afirmam que aos exemplos oferecidos por Freud podemos ainda adicionar alguns outros, mais próximos de nosso cotidiano: "a palavra estranhar é comumente utilizada para a situação em que o cão não reconhece seu dono ou alguém conhecido, ou seja, uma situação que deveria lhe ser familiar. E curiosamente, em espanhol, estrañar significa 'sentir saudades' - remete a algo familiar que não está mais presente". De posse de tais ambiguidades desse tipo, Freud aponta que o estranho é tudo aquilo que, devendo permanecer oculto, acabou se manifestando.

De acordo com Saceanu (2001), nesse texto Freud trabalha o conto de Hoffmann, ou Ernst Theodor Amadeus Wilhelm Hoffmann, escritor alemão, nascido no século XVII, que é considerado o "mestre do fantástico" e que tem o título $O$ homem da areia. A análise criteriosa de Freud tem como objetivo cotejar a hipótese de acordo com a qual o estranho remeteria àquilo que nos é mais intimamente familiar. 
Em linhas gerais, o conto aborda, inicialmente, as lembranças infantis de Natanael, personagem principal, um jovem que não consegue abolir as lembranças vinculadas à morte de seu pai, considerada misteriosa. Ele descreve os fatos que lhe aconteceram e uma repentina aparição que lhe evocara terríveis pressentimentos e lhe remeteram à história do Homem da areia, "aquele que joga areia e arranca os olhos das crianças desobedientes", figura que tanto lhe apavorava quando era criança e ouvia as histórias contadas por sua mãe (SACEANU, 2001). Ainda podemos acrescentar a contribuição de uma governanta que cuidou de Natanael e lhe dizia que o "Homem da areia" é um homem mau que se aproxima das crianças quando elas não querem ir para a cama e lhes joga um punhado de areia nos olhos; estes então saltam sangrando da cabeça, e ele os coloca num saco e os leva para a lua, a fim de alimentar suas criancinhas, que lá ficam no ninho e têm bicos retorcidos como corujas, com os quais comem os olhos das crianças travessas.

Natanael acredita reconhecer este fantasma de horror de sua infância na figura de um vendedor de instrumentos óticos que lhe aparece de modo repentino. Associa ainda este personagem com o advogado Coppelius, um homem que também lhe causava horror quando criança. O jovem suspeitava que Coppelius, este homem assustador, teria alguma ligação com a morte de seu pai. (SACEANU, 2001).

A figura de Coppelius é assim descrita por Costa (2006, p. 79):

Coppelius, segundo a descrição de Natanael, era um homem de costas largas, com uma cabeça grande e disforme, rosto amarelo-terra, sobrancelhas espessas e cinzentas, sob as quais faiscava um par de esverdeados olhos de gato, um nariz forte e grande, bem proeminente sobre o lábio superior. A bocarra torta frequentemente era retorcida por uma risada de escárnio; nestes momentos, tornavam-se visíveis em sua face algumas manchas vermelho-escuras, enquanto um chiado estranho escapa pelos dentes cerrados. Coppelius vinha sempre vestido com um sobretudo fora de moda, de cor cinza, como também as calças e o colete; além disso, usava meias pretas e sapatos com pequenas fivelas de pedraria. A pequena peruca mal cobria a base da cabeça, alguns cachos postiços estavam colados bem acima das grandes orelhas vermelhas, e um grande coque eriçado na nuca deixava à mostra a fivela prateada do colarinho pregueado. Enfim, a figura toda era horrível e abjeta, mas para as crianças o mais repugnante eram suas mãos ossudas e peludas, de tal forma que elas recusavam tudo que ele houvesse tocado. Após ter percebido isso, Coppelius encontrava grande prazer em tocar, sob este ou aquele pretexto, alguma fatia de bolo ou de fruta madura que a mãe tivesse posto furtivamente nos pratos, fazendo-os rejeitar, por nojo ou aversão e com lágrimas nos olhos, as gulodices que deveriam alegra-los. O mesmo ele fazia em dias de festa, quando o pai oferecia a elas um pequeno cálice de vinho doce. Então, rapidamente, ele passava a mão pela borda do cálice, ou até mesmo o levava aos lábios azulados, rindo de maneira deveras diabólica quando as crianças ousavam manifestar seu desgosto, apenas com mansos soluços. Ele costumava chamá-las de "pequenas bestas". Elas não tinham 
permissão para abrir a boca em sua presença, e amaldiçoávamos o homem feio e hostil, que estragava nossas menores alegrias com deliberada má intenção.

No conto, Natanael ainda narra quando já era um estudante, o seu encontro com Coppola, um vendedor de instrumentos óticos que lhe desperta horror pela semelhança com os fantasmas de sua infância. Porém, Coppola, também lhe causa certa atração, pelos instrumentos óticos que negociava. Natanael compra, na mão dele, um pequeno binóculo, e passa, através dele a observar Olímpia pela janela, apaixonando-se cegamente por ela, sem perceber, no entanto, que se tratava de uma boneca (SACEANU, 2001).

Saceanu (2001) ainda acrescenta que,

\begin{abstract}
Após um acesso de loucura ao perceber Olímpia como uma boneca de fato, a quem faltavam os olhos, Natanael parece recuperado e volta para sua noiva, Clara. Porém, a última passagem do conto mostra que o horror continuava. Do alto de uma torre, acompanhado de Clara, Natanael observa através de seu binóculo a aproximação do terrível advogado Coppelius, o que lança o jovem novamente em um ataque de loucura. Transtornado, tenta atirar a noiva do alto da torre, terminando por lançar-se por sobre o parapeito, enquanto o Homem da Areia (Coppelius) desaparece na multidão.
\end{abstract}

\title{
1 O ESTRANHO E A PSICANÁLISE
}

A partir desse texto de Freud, podemos então pensar o estranho em relação ao familiar e, assim, também, pensar na própria proposta da Psicanálise com relação a tal tema.

Freud apontou que a Psicanálise produziu a terceira ferida narcísica sofrida pelo saber ocidental ao causar um descentramento da razão e da consciência (as outras duas feridas foram produzidas por Copérnico, quando ele retira a terra do centro do universo, e por Darwin, que retira o homem do topo da cadeia animal).

Sem suspeita alguma, a Psicanálise determinou uma derrubada da razão e da consciência do lugar de destaque e supremacia que se encontravam. Ao fazer da consciência um mero efeito de superfície do inconsciente, Freud operou uma inversão do cartesianismo que não pode ser negada. A partir desse momento, a subjetividade deixa de ser entendida como um todo, unitário, sinônimo de consciência e sob o domínio da razão, para tornar-se uma realidade composta por dois grandes sistemas - o inconsciente e o consciente - e dominada por uma luta interna em relação à qual a razão é apenas um efeito de superfície. 
De acordo com Garcia-Roza (2009), uma das maneiras de se começar a falar no inconsciente freudiano pode ser a de se apontar o que ele não é ou, então, a de se marcar a sua diferença com relação àquela concepção de subjetividade dominante até Freud, que se identificava com a consciência e dominada pela razão, como já citado. O termo "inconsciente", quando empregado antes de Freud, o era de uma forma puramente adjetiva para designar aquilo que não era consciente, mas jamais para designar um sistema psíquico distinto dos demais e dotado de atividade e lógica próprias.

Um outro aspecto importante a ser destacado é o da identificação do inconsciente como caos, o mistério, o inefável, o ilógico etc., e essa identificação ocorreu tanto anteriormente a Freud como no interior do próprio espaço do saber psicanalítico. Até hoje nos deparamos com tais "descrições" do inconsciente como sendo o lugar da vontade em estado bruto e impermeável a qualquer inteligibilidade. A esse respeito Lacan declara que "o inconsciente de Freud não é de modo algum o inconsciente romântico da criação imaginante. Não é o lugar das divindades da noite" (GARCIA-ROZA, 2009).

Freud aborda, então, a constituição de um sistema psíquico composto pelo ICS (Inconsciente) - que se contrapõe a outro sistema psíquico - o PCS/CS (Préconsciente/Consciente) - que é em parte inconsciente (adjetivamente), mas que não é o sistema inconsciente.

Freud assinala que é nas "lacunas" das manifestações conscientes que temos que procurar o caminho do inconsciente. Essas lacunas vão trazer para o primeiro plano da investigação psicanalítica aquilo que Lacan, seguindo Freud, chamou de "formações do inconsciente" ou ainda manifestações do inconsciente: o sonho, o ato falho, o chiste e os sintomas.

Podemos expor que um dos marcos da história de Sigmund Freud e da Psicanálise foi sua obra de 1900, A interpretação dos sonhos. Essa obra, a princípio não teve importância e reconhecimento, mas posteriormente obteve seu devido valor. Através dela, foi possível observar que no processo, o fenômeno sonhar traz o inconsciente de uma forma reveladora e acessível. Temos que concordar com Freud de que o cotejamento sobre os sonhos é o caminho para uma estrada que leva aos recessos inconscientes e obscuros da mente, ou ainda a "estrada real" para o inconsciente. 
Os sonhos são caracterizados por conteúdos denominados manifestos e latentes e fazer a distinção desses conteúdos foi, para Freud, uma via de encontro com a estranheza que eles produzem nas pessoas. Os conteúdos latentes dos sonhos indicam manifestações do inconsciente e são necessários métodos exclusivos para se entender o seu real significado. Feito isso, os sonhos acabavam se revelando como desejos inconscientes sempre com material recalcado e infantil, indicando uma relação com algo de caráter sexual.

Assim, diferentemente do que o senso comum acredita, os sonhos possuem sentido para o sonhador, e demandam um trabalho de interpretação, que somente o sonhador pode operar.

Os atos falhos, outra forma de manifestação do inconsciente, são atos em que o resultado explicitamente visado não é atingido, pois se acha substituído por um outro. Os atos falhos se expressam nas falhas das palavras, da memória, da ação, que o senso comum atribui apenas à falta de atenção ou ao acaso. Assim, para a Psicanálise, o ato falho é um ato bem sucedido: o desejo inconsciente realiza-se nele de uma forma manifesta.

No que diz respeito aos chistes, podemos observar que, de acordo com Morais (2008), Freud já dava importância a eles nos primórdios da Psicanálise. Em sua correspondência com Fliess, especialmente em uma carta 12/06/1897, ele cita seu interesse por piadas sobre judeus e confessa que colecionava uma série delas. Em 1905, Freud publica o texto Os chistes e sua relação com o inconsciente, e nele vemos seu esforço em descobrir o que faz com que uma piada seja objeto do riso, e o que é o riso para a economia psíquica. A autora acrescenta ainda que, “[...] enquanto o sonho é solipsista, só envolve o sonhador (a não ser quando narrado), o chiste é a formação do inconsciente que mais se insere no social, necessita do outro para referendá-lo".

\footnotetext{
O termo Witz, traduzido na edição brasileira por Chiste, tem raízes no romantismo alemão e é de difícil tradução para o português. Os franceses preferiram esprit, espírito, o dom de quem é espirituoso. Podemos traduzir do alemão por dom de contar acertadamente algo alegre e divertido, dom de replicar pronta e alegremente, graça de espírito, o espírito da coisa, inteligência, engenhosidade, esperteza. O termo remete também para a um saber alegre. Consideraremos tanto as piadas quanto o humor apresentações privilegiadas do chiste. É um dito espirituoso, um humor fino. (MORAIS, 2008).
} 
Freud, então, destaca que no chiste e na sua produção do humor também encontramos os mesmos mecanismos da condensação e deslocamento, através dos quais o inconsciente se manifesta, como nos sonhos, atos falhos e sintomas. O chiste permite que alguma coisa da ordem do recalcado se mostre, sem pagar o preço neurótico da angústia ou do padecimento dos sintomas. O humor age como álibi de alguma verdade do sujeito que, até então, não fora capaz de ser dita. "Numa brincadeira pode-se até dizer a verdade", enuncia Freud no seu livro Os chistes e sua relação com o inconsciente. "Foi sem querer querendo, como diz o Chavez do programa humorístico da TV. Esta verdade se diz através de um sentido insólito brotado do non-sense, do paradoxo, do absurdo, ao qual se segue uma revelação de sentido, que é sempre surpreendente e fugaz, seguido da descarga do riso" (MORAIS, 2008). Dessa forma, a tentativa de explicar o chiste promoveria a perda do seu sentido humorístico.

E por último temos o sintoma. De acordo com Garcia-Roza (2009, p. 55), para a Medicina, o sintoma se apresenta como um indicativo de uma determinada doença, mas para a Psicanálise seu estatuto é outro: a expressão de um conflito inconsciente. Freud inicia sua obra pelo sintoma, da histeria, particularmente, portanto por aquilo que vai mal. Sua posição era que os sintomas neuróticos podiam ser interpretados, pois tinham um sentido, da mesma forma que os atos falhos e os sonhos. "O sintoma no sentido analítico, ou em sua significação clássica, quer dizer aquilo que é analisável, a verdade do sujeito. A possibilidade de interpretação advém do sintoma como portador de uma mensagem cifrada".

Dessa forma, o que é destacado, de acordo com o mesmo autor, nesses fenômenos chamados lacunares é, simultaneamente, a descontinuidade que eles produzem no discurso consciente, mas também um sentimento de ultrapassagem que os acompanha. Neles, o sujeito sente-se como que atropelado por um outro sujeito que ele desconhece, um estranho, mas que se impõe em seu discurso produzindo trocas de nomes e esquecimentos, por exemplo, cujo sentido lhe escapa. É essa perplexidade e esse sentimento de ultrapassagem que funcionarão como referentes para o sujeito, referentes de um outro sujeito oculto e em oposição a ele. Esse outro sujeito é o sujeito do inconsciente.

Os fenômenos lacunares são, portanto, indicadores de uma outra ordem, irredutível à ordem consciente e que se insinua nas lacunas e nos silêncios dessa última. Essa outra ordem é a do inconsciente, estrutura segunda, e que não é apenas topograficamente distinta da consciência, 
mas é formalmente diferente desta. O inconsciente não é o mais profundo, nem o mais instintivo, nem o mais tumultuado, nem o menos lógico, mas uma outra estrutura, diferente da consciência, mas igualmente inteligível (GARCIA-ROZA, 2009).

Assim, observamos que as formações do inconsciente, ou as formas de manifestação do inconsciente, se mostram como uma reaparição indesejada do que era para ficar oculto. O que se impõe é o mecanismo do recalque, conceito proposto por Freud, entendido como sendo de importância capital na estruturação e funcionamento do aparelho psíquico.

O recalque é uma operação psíquica interna pela qual o sujeito procura repelir ou manter no inconsciente representações (pensamentos, imagens, recordações) que são ligadas a uma pulsão (energia psíquica postulada por Freud que circula no aparelho psíquico, que a difere do instinto que é de ordem animal). O recalque produz-se nos casos em que a satisfação de uma pulsão - suscetível de por si mesma proporcionar prazer - ameaçaria provocar desprazer relativamente a outras exigências. O recalque se distingue da repressão, que se caracteriza por ser uma operação externa (GARCIA-ROZA, 2009).

Com o objetivo de manter o campo da consciência livre de excitações conflitivas, operase o afastamento destas, bem como uma espécie de confinamento à uma outra "outra cena", no caso, o inconsciente. Mas tal tendência recalcadora não obtém por completo seu intento, e observamos a revelação de seu fracasso, quando, por vias distorcidas, ocorre seu retorno nessas manifestações, o seja, o retorno do recalcado.

Mas, aqui, podemos pensar em uma outra manifestação do estranho, em sua, digamos, radicalidade que se apresenta através da loucura, loucura que também é descrita na obra de Hoffman.

O século XVII foi aquele que marcou a separação entre a razão e desrazão; produzindo a emergência da loucura. Desde o trabalho publicado por Michel Foucault, História da loucura, em 1978, temos uma descrição minuciosa das condições em que isso ocorreu. Para Foucault (1991), a loucura não existia, o que existia era a diferença e o lugar produzido por ela. Assim o louco ocupava um espaço juntamente com o alcoólatra, o vagabundo, o delinquente, o sifilítico ou o que restava dos leprosos. O louco como uma entidade diferenciada não existia antes do século XVII. 
De acordo com Ribeiro (2011, p. 55), Foucault nos expõe que a loucura é uma fabricação do século XVIII, através de seus saberes, das suas práticas, das suas instituições. O louco é o efeito da convergência de, principalmente, duas séries, a série asilar e a série médica. "Isso não significa dizer que a loucura não existia, ou melhor, que ela tenha passado a existir desde então; significa dizer que ela foi fabricada, sendo que a grande fábrica foi o hospital e que, o grande artesão foi o psiquiatra".

A partir desse referencial a loucura passa a ser objeto de um controle disciplinar, e o louco não aquele que deveria ser objeto de cura, mas domesticado. Assim, observamos que a loucura, ao passar a ser objeto de um saber, o saber médico, e também com o aparecimento do hospital psiquiátrico, no século XVIII, ganha um novo estatuto, o de enfermidade, que deverá ser tratada no âmbito de tais hospitais. A função precípua de tais hospitais se circunscrevia a fazer o diagnóstico das patologias mentais e tratá-las de acordo com o conhecimento médico psiquiátrico, bem como manter a loucura longe dos olhares da sociedade. (RIBEIRO, 2011). Segundo o psicanalista Joel Birman (apud RIBEIRO, 2011), o discurso sobre a enfermidade mental permitiu a exclusão social dos loucos, e teve como consequência a destituição de seus direitos. Assim o saber psiquiátrico alça o louco à condição de objeto de estudo.

\footnotetext{
O saber médico concebia o hospital psiquiátrico como dispositivo de ação curativa indispensável para o tratamento da loucura, lugar constituído por práticas e meios adequados para aliviar ou curar o sofrimento dos loucos. O isolamento e a vigilância eram formas marcantes dos hospitais psiquiátricos tratarem a questão da loucura. As instituições psiquiátricas exerciam um domínio permanente, assumindo a responsabilidade total da vida dos pacientes. O olhar constante da instituição cerceava a circulação dos loucos, que eram observados em todos os momentos e lugares, dentro do hospital psiquiátrico, restando-lhes vagar por entre os corredores à espera dos doutores da razão, senhores incontáveis de mapas, que conduziriam à cura. (RIBEIRO, 2011, p. 66).
}

Assim, isolar o louco em uma instituição psiquiátrica visava, também, a possibilidade de uma posterior reinserção na sociedade, após tratamento apropriado que teria como consequência sua recuperação. “Toda a técnica e o procedimento praticados nos hospitais psiquiátricos tinham 'por função fazer do personagem médico, o mestre da loucura', segundo Foucault. Cabia ao médico desvelar as verdades intrínsecas ao louco". (RIBEIRO, 2011, p. 70).

Lima Filho acrescenta que o controle tanto do sujeito sobre outro sujeito, ou ainda sobre si próprio, cria normas e leis rígidas, que têm como intuito disciplinar corpos e mentes. Tal 
disciplinamento objetiva também controlar a estranheza de cada um, forças estranhas e avassaladoras que ameaçam perenemente todas as sociedades.

\footnotetext{
$\mathrm{Na}$ tentativa de aplacar o estranho-familiar e controlá-lo, se criam "diques" por onde possam escoar o estranho. Os "diques" nada mais são do que as diferentes representações culturais ou espaços-lugares instituídos pela cultura (religiões, escolas, valores, tabus etc.) para acolher e simbolizar o estranho-familiar que habita o sujeito de linguagens. (LIMA FILHO, 2017).
}

Ainda para o mesmo autor, o limite que separa o racional do irracional, o consciente do inconsciente, a normalidade da loucura é tênue. "O sujeito é constituído por esses paradoxos, podendo ser a loucura concebida como a estranheza que habita o sujeito, porém devendo ser repelida pelo mesmo, pois é fonte de ameaça devido sua força avassaladora, disruptiva".

\section{À GUISA DE CONCLUSÃo}

Nesse ponto torna-se aqui necessária uma interrogação: tudo que evoca conteúdos recalcados ou formas de pensamento superadas é forçosamente sinistro, estranho? Quem nos traz essa resposta é o psicanalista Oscar Cesarotto em seu livro No olho do outro, no qual ele nos expõe que, para ser dessa ordem, algumas condições necessitam ser cumpridas. Uma delas, a que nos interessa neste caso, refere-se às consequências terríveis da realização do desejo.

Mas o que vem a ser o desejo para a Psicanálise?

O desejo para a Psicanálise, diferentemente da compreensão defendia pela biologia, por exemplo, que o vincula com a satisfação de uma necessidade, remete a uma ordem simbólica. Ele sempre demarca uma falta e não para num objeto que possa ser empiricamente considerado. Assim, deslocando de objeto em objeto, o desejo desliza numa série infinita, numa satisfação nunca atingida e para sempre adiada.

Freud nos ensinou que o objeto do desejo é um objeto perdido, uma falta, e que esse objeto perdido para sempre mantém sua presença como falta. A falta é, assim, a condição fundamental do sujeito e de sua humanidade. 
Com efeito, sendo a presença de uma ausência a causa do desejo, é consubstancial à sua estrutura que este espaço vazio assim permaneça, para permitir certa liberdade de ação. Se a carência for preenchida, some a tensão que mantém a vida na expectativa, e se perde a razão de existir. Para evitar o perigo da queda nesta fruição insensata, não se pode prescindir da incompletude. (CESAROTTO, 1996, p. 45)

Isso então equivale a dizer que o sujeito não é senhor de si mesmo, ele é para sempre um estrangeiro, um estranho em sua própria casa, movido pela força do desejo, que é responsável pelos caminhos tortuosos trilhados por cada um de nós.

\section{REFERÊNCIAS}

COSTA, Flávio Moreira da (Org.). Os melhores contos fantásticos. Rio de Janeiro: Nova Fronteira, 2006. Disponível em:

file://C:/Users/samsunf/Downloads/Os $\% 20$ melhores $\% 20$ contos $\% 20$ fant $\% \mathrm{C} 3 \% \mathrm{~A} 1$ sticos\%20(2).pdf. Acesso em: 20 maio 2017.

CESAROTTO, Oscar. No olho do outro. São Paulo: Iluminuras, 1996.

FOUCAULT, Michel. História da loucura na idade clássica. $3^{\text {a }}$. ed. São Paulo: Perspectiva, 1991.

GARCIA-ROZA, Luiz Alfredo. Freud e o inconsciente. Rio de Janeiro: Jorge Zahar, 2009.

LIMA FILHO, Ivo de Andrade. A estranheza da linguagem e a clínica das psicoses. Disponivel em:

http://www.fundamentalpsychopathology.org/uploads/files/ii_congresso_internacional/temas_livr es/ii_con._a estranheza da linguagem_e_a clinica_das psicoses tl.pdf. Acesso em: 20 maio 2017.

MARTINI, André de; COELHO JÚNIOR, Nelson Ernesto. Novas notas sobre "O estranho".

Tempo Psicanalítico, Rio de Janeiro, v.42, n. 2, 2010. Disponível em: http://pepsic.bvsalud.org/scielo.php?script $=$ sci arttext\&pid $=$ S0101-48382010000200006. Acesso em: 20 maio 2017.

MORAIS, Marília Brandão Lemos. Humor e Psicanálise. Estudos de psicanálise, Belo Horizonte, n.31, 2008. Disponível em:

http://pepsic.bvsalud.org/scielo.php?script $=$ sci arttext\&pid $=$ S0100-34372008000100014. Acesso em: 20 maio 2017.

RIBEIRO, Fabrício Junio Rocha. Da razão ao delírio: por uma abordagem interdisciplinar do conceito de loucura. Curitiba: Juruá, 2011. 
SACEANU, Patrícia. O estranho e seus destinos. 2001. 122 f. Dissertação (Mestrado) Programa de pós-graduação em teoria psicanalítica do Instituto de Psicologia da Universidade Federal do Rio de Janeiro, Rio de Janeiro, 2001. Disponível em:

$<$ http://teopsic.psicologia.ufrj.br/arquivos/documentos/A580EC1F52416204F942981734514657. pdf>. Acesso em: 20 maio 2017. 